\title{
Multistep Mass-Remainder Analysis and its Application for Copolymer Blends
}

Tibor Nagy ${ }^{1}$, Ákos Kuki $^{1}$, Mahir Hashimov ${ }^{1,2}$, Miklós Zsuga ${ }^{1}$, Sándor Kéki ${ }^{1 *}$

${ }^{I}$ Department of Applied Chemistry, Faculty of Science and Technology, University of Debrecen, $\mathrm{H}$ 4032 Debrecen, Egyetem tér 1., Hungary

${ }^{2}$ University of Debrecen, Doctoral School of Chemistry, H-4032 Debrecen, Egyetem tér 1., Hungary.

* Corresponding author: keki.sandor@science.unideb.hu, fax: +36 52 518662; H-4032 Debrecen, Egyetem tér 1., HUNGARY

\section{Table of content}

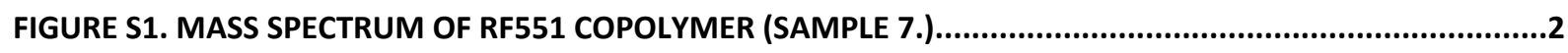



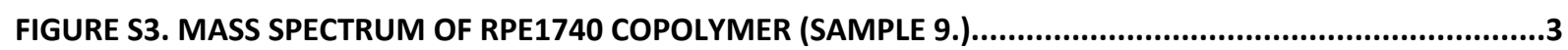

FIGURE S4. KMD PLOT OF EO/PO COPOLYMER BLEND (SAMPLE 6.) ............................................................ 


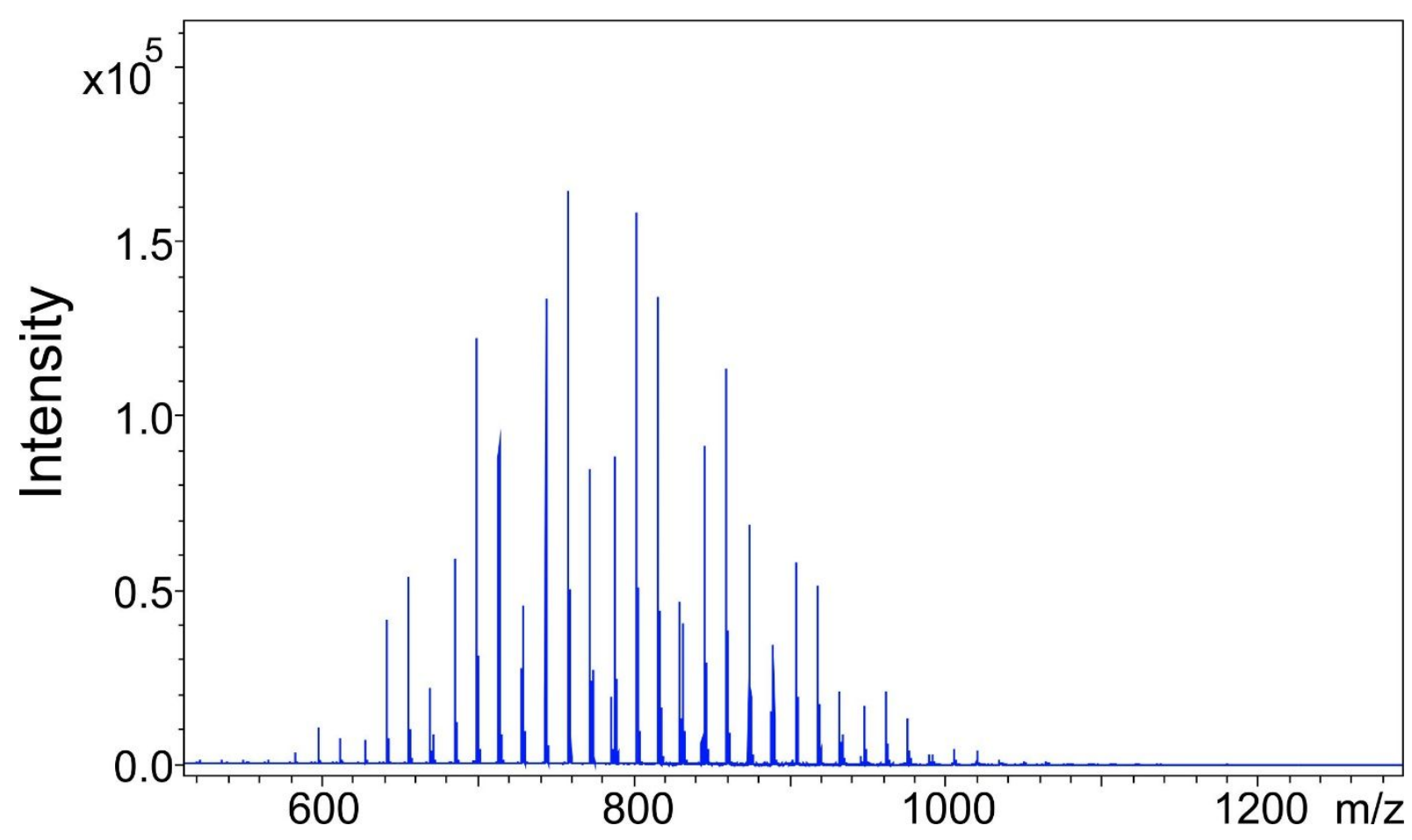

Figure S1. Mass spectrum of RF551 copolymer (Sample 7.)

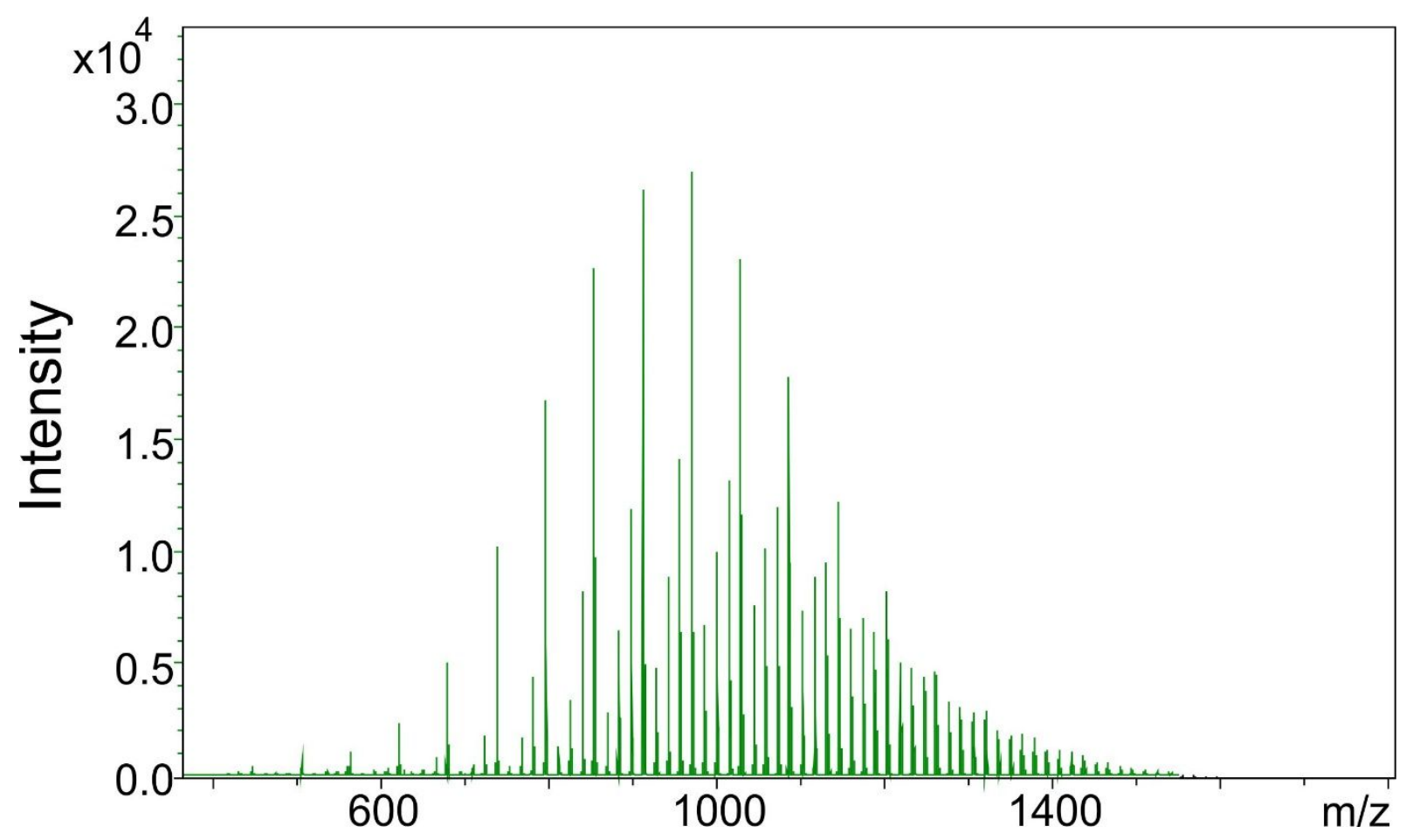

Figure S2. Mass spectrum of PE3100 copolymer (Sample 8.) 


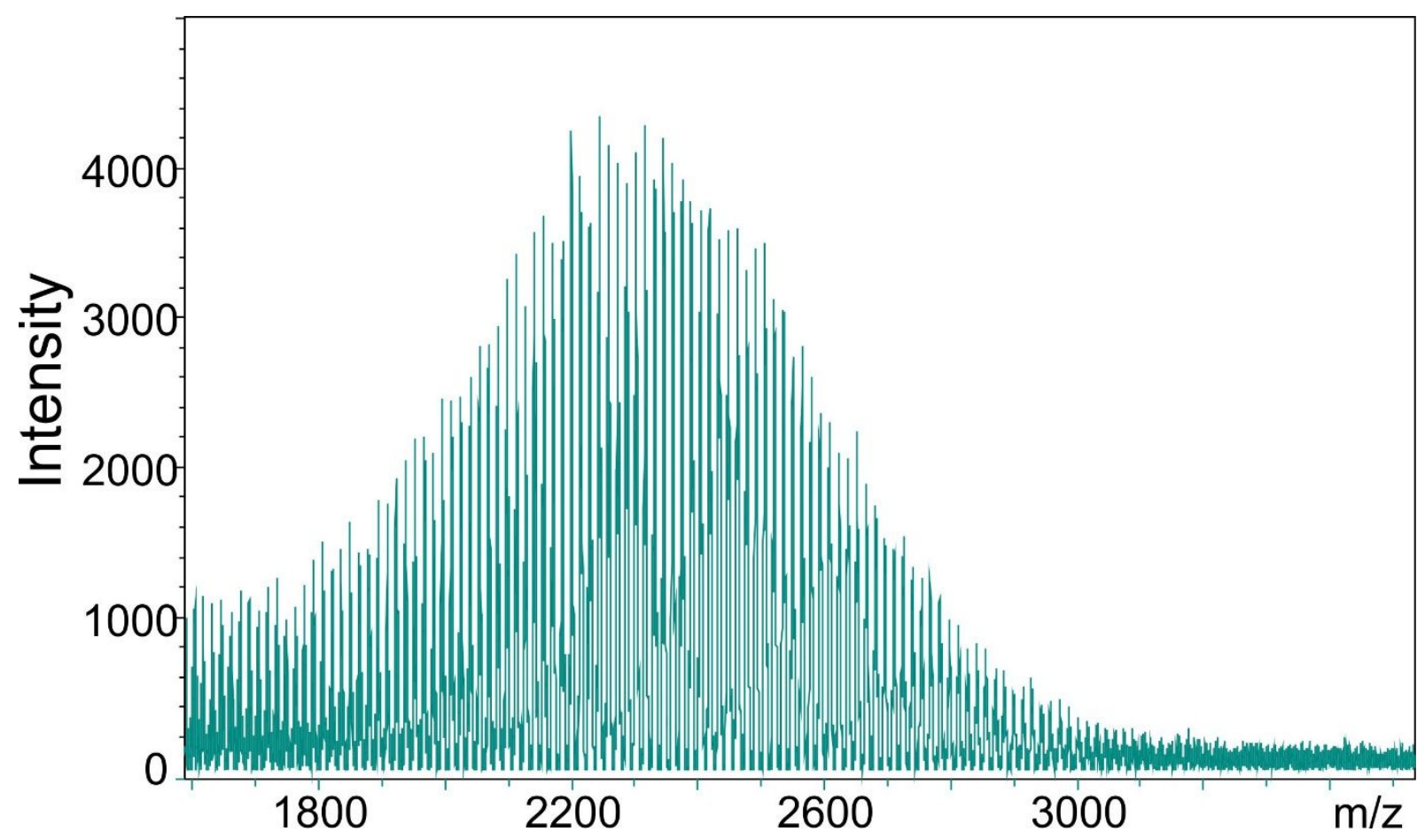

Figure S3. Mass spectrum of RPE1740 copolymer (Sample 9.)

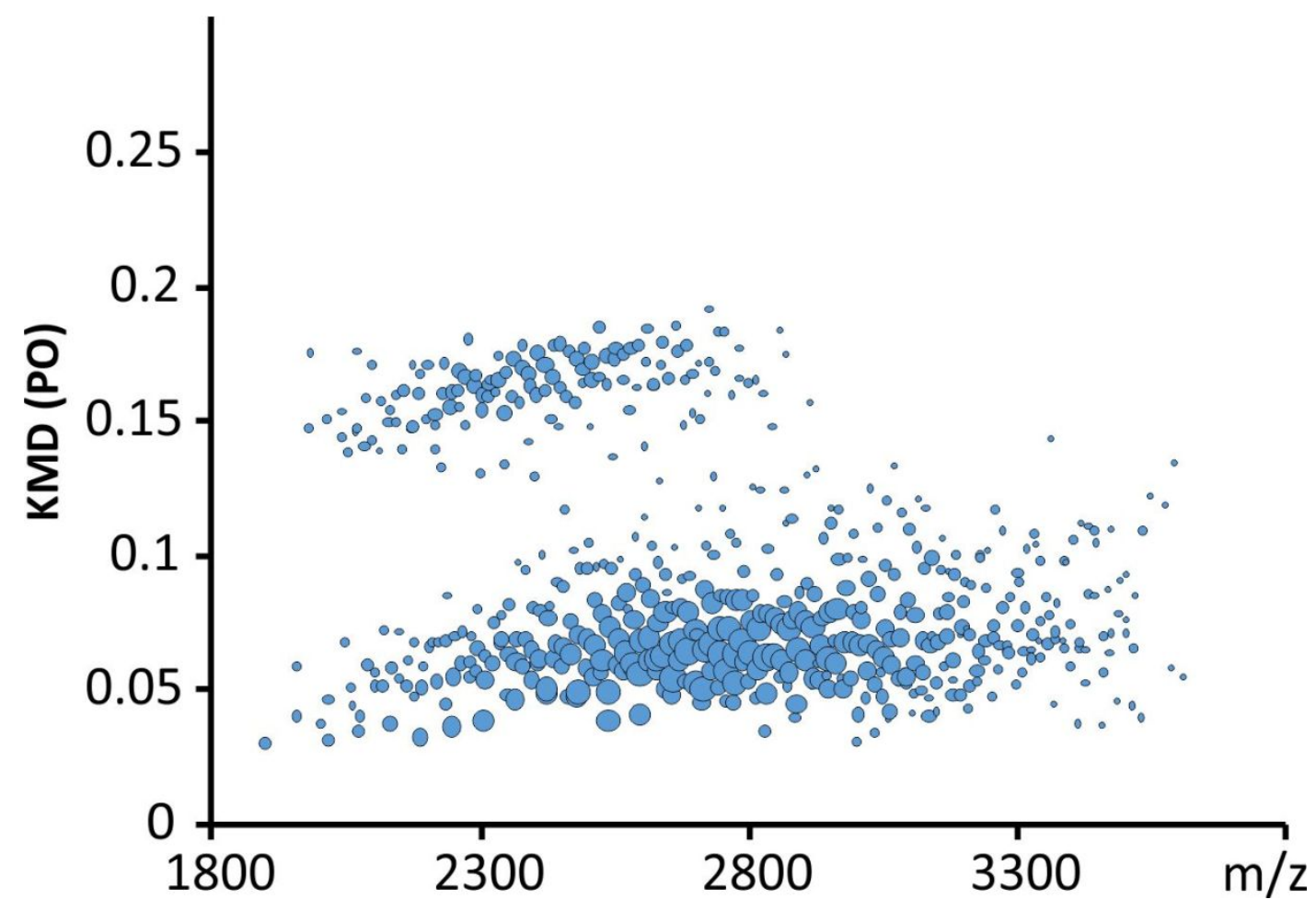

Figure S4. KMD plot of EO/PO copolymer blend (Sample ‥) 